\title{
THE USE OF MANTRA IN THE TRADITION OF MAITAI ALLO MACOA IN ONGLO PEOPLE CAMPALAGIAN SUBDISTRICT POLMAN REGENCY : A REVIEW OF THE SEMIOTICS
}

\author{
${ }^{1}$ Hajaratul Aswad, ${ }^{2}$ Nurhayaty, ${ }^{3}$ Ikhwan said \\ ${ }^{1,2,3}$ Program Studi linguistik, Fakultas Ilmu Budaya,Universitas Hasanuddin, \\ Makassar \\ Hayaraswad@gmail.com \\ Nurhayatisyair@gmail.com \\ Ionesaid@gmail.com
}

\begin{abstract}
The aims of this research were to decipher and to explain interaction between spell and Maitai Allo Macoa tradition, the exsistence of spell and tradition of Maitai Allo Macoa especially to sociaty in Ongko village. The content of spell is the old poem that consist of proface and cloosing. Whereas the manuscript is a creation of cultural that used the symbols and have meaning. This study was qualitative research that orient to the words in the form of spelling and the manuscript of symbols of Maitai Allo Macoa. This research was done in Ongko village sub regency Campalagian, Polman regency. The data were gained by observation, either close and open interview to society, recorded and written. The result of this research showed that the sociaty usually used the spell in the manuscript of Maitai Allo Macoa before going to wander. It consists of there kinds of spell and one manuscript; pembueang, peakkeyang, assalamakang and Maitai Allo Macoa manuscript. In general, the spelling manuscript has relationship to the Holy Al-Qur'an text. It means the creation of spelling inspired by Holy Alquran. Things that decide the good day in the manuscript are time and symbol meaning which are used as the direction to held the holy activity. The exsistence or effect on the using of the spell and tradition of Maitai Allo Macoa is success and safety.
\end{abstract}

Keywords: the spell of wander, manuscript of Maitai Allo Macoa.

\section{PENDAHULUAN}

Dewasa ini telah diketahui bahwa bahasa adalah kekayaan budaya yang menunjukan Identitas dari setiap kelompok suku, ras dan agama. Bahasa sebagai representasi keunikan penuturpenuturnya dalam memandang dunia dan sekitarnya (Wijana dan Muhammad, 2006)

Keraf (dalam Smarapradhipa 2005:1) memberikan dua pengertian bahasa yakni pertama, menyatakan bahwa bahasa sebagai alat komunikasi antara anggota masyarakat berupa simbol bunyi yang dihasilkan oleh alat ucap manusia, dan kedua, bahasa adalah sistem komunikasi yang mempergunakan simbol-simbol vokal (bunyi ujaran) yang bersifat arbitrer.

Salah satu bentuk ungkapan bahasa sebagai produk kebudayaan ialah penggunaan mantra dalam kehidupan masyarakat. Mantra lahir dari masyarakat sebagai perwujudan atas keyakinan atau kepercayaan. Masyarakat tradisional memandang bahwa, mantra bersatu dan menyatu dalam kehidupan sehari-hari, seorang pawang atau dukun yang ingin menyembuhkan penyakit misalnya, dilakukan dengan membacakan mantra. Berbagai kegiatan dalam pembacaan mantra dilakukan oleh dukun atau pawang dan masyarakat tradisional itu sendiri, terutama yang berhubungan dengan adat, tradisi dan budayanya.

Mantra dan masyarakat memiliki hubungan yang erat. Artinya, mantra ada karena ada masyarakat pewarisnya. Lahirnya mantra di tengah-tengah masyarakat merupakan suatu perwujudan 
atas kepercayaan dan keyakinan yang dimilikinya. Berdasarkan informasi dari hasil penelitian diketahui bahwa mantra terdiri atas beberapa tujuan seperti yang telah dikemukakan oleh Rusyana (1970) dalam hasil penelitiannya membagi mantra berdasarkan tujuannya menjadi 7 bagian yaitu: (1) Jampe (jampi), (2) Asihan (pekasih), (3) Singlar (pengusir), (4) Jangjawokan (ampi), (5) Rajah (kata-kata pembuka jampi), (6) Ajian-ajian (jampi ajian kekuatan), dan (7) Pelet (Gunaguna). Diketahui bahwa ketujuh bagian tersebut dapat dikelompokkan ke dalam mantra putih 'white magic' dan mantra hitam 'black magic'.

Dapat dicermati pula bahwa mantra puth di antaranya bertujuan menguasai jiwa orang lain, agar diri dalam keunggulan, agar disayang, agar maksud berhasil dengan baik, agar perkasa dan awet muda, berani, agar selamat, untuk menjaga harta benda, mengusir hantu atau roh halus, menaklukan binatang, menolak santet, untuk menyembuhkan orang sakit. Adapun kategori mantra hitam di antaranya bertujuan mencelakai orang agar sakit atau mati, membalas perbuatan jahil orang lain, dan memperdayakan orang lain karena sakit hati. Kehadiran mantra putih maupun mantra hitam itu sendiri berpangkal pada kepercayaan masyarakat pendukung di dalamnya yang memunculkan fenomena yang semakin kompleks di jaman sekarang.

Tradisi "Maitai Allo Macoa" merupakan warisan nenek moyang terdahulu yang dipercaya sebagai kegiatan menentukan waktu dalam hari yang dianggap baik untuk memulai peperangan. Hingga saat ini, tradisi "Maitai Allo Macoa" masih digunakan secara turuntemurun oleh masyarakat Desa Ongko. Pada awalnya tradisi "Maitai Allo Macoa" hanya digunakan oleh Manyam Bumi, yaitu Raja Balanipa X untuk menentukan waktu dalam hari yang dianggap baik dan tepat dalam berangkat ke medan perang untuk memulai pertempuran. Seiring perkembangan zaman dari masa ke masa, tradisi "Maitai Allo macoa" juga mulai digunakan dalam berbagai hal, yaitu berangkat berdagang untuk menjual dagangan, berangkat mencari pekerjaaan atau menuntut ilmu di tanah rantauan, menentukan waktu dalam hari untuk memulai acara pernikahan atau untuk membangun rumah, dan menentukan waktu dalam hari untuk memulai acara kegiatan adat.

Mengenai serangkaian penggunaan mantra di dalam tradisi "Maitai Allo Macoa" hal demikian dilakukan dengan mengacu pada teks naskah yang sudah dijelaskan secara lengkap dan terperinci. Selain itu, informasi tentang penggunaan mantra dalam tradisi "Maitai Allo Macoa" dapat dibagi menjadi lima jenis berdasarkan teks dan tujuan penggunaannya yaitu:

1. Mantra Bangun tidur (Paissangang Pembueang)

2. Mantra pemberangkatan (Paissangang Peakkeyang)

3. Mantra Keselamatan (Paissangang Assalamang)

4. Mantra Pengasih (Paissangang Pakkesayang)

5. Mantra Mendatangkan rezeki (Paissangang Peppoleang dalle

Penggunaan mantra dalam tradisi yang dikemukakan di atas diyakini mampu mendatangkan kekuatan gaib yang bisa membantu dan memudahkan pembaca mantra guna mendapatkan apa yang ingin dicapai dalam perantauan.

Berdasarkan hasil penelitian sebelumnya tentang bahasa mantra yang dilakukan oleh Saputra dan Puji (2013) berjudul "Tradisi Santet sebagai Pranata Budaya Lokal : Kajian Kelisanan Mantra Sabuk Mangir dan Jaran Goyang dalam Budaya Banyuwangi" yang mana penelitian tersebut membahas tentang perbandingan antara varian teks mantra Sabuk Mangir dan mantra Jaran Goyang ditinjau dari teori formula sintaktis, formula repetisi yang bervariasi, dan 
formula repetisi tautotes. Teori ini dipopulerkan oleh Parry dan Lord, yang kemudian dikenal sebagai teori formula Parry-Lord. Pendekatan yang digunakan ialah pendekatan struktural dan etmografi. Dari hasil penelitian tersebut dapat dikatakan bahwa belum memberikan penjelasan yang komprehensif tentang bagaimana hubungan antara mantra dan tradisi serta makna yang terkandung dalam mantra itu sendiri. Dengan kata lain, hasil penelitian tersebut belum mengkaji secara spesifik makna yang terkandung dalam mantra Sabuk Mangir dan Jaran Goyang pada masyarakat Banyuwangi baik secara lingusitik maupun berkaitan dengan pendekatan semiotik dalam konteks tradisi dan konteks budayanya.

Oleh karena itu, penelitian ini akan memfokuskan tentang makna mantra yang terkandung dalam tradisi "Maitai Allo Macoa" dan kaitan antara bahasa mantra dalam tradisi tersebut dengan pendekatan semiotika, yaitu bahasa dilihat dari dalam dirinya (leksikogramatika) dan peranannya dalam kelompok tertentu sebagai pengungkapan gagasan atau konsep (Sutjaja, 1990:69).

Dengan demikian tujuan penilitian ini, yaitu (i) menjelaskan hubungan penggunaan mantra dalam "Tradisi Maitai Allo Macoa" pada masyarakat Desa Ongko, Kec. Campalagian, Kab. Polman, (ii) menjelaskan makna mantra yang terkandung dalam tradisi "Maitai Allo Macoa" pada masyarakat Desa Onko, Kec. Campalagian, Kab. Polewali Mandar dalam tinjauan Semiotika, dan (iii) menjelaskan Dampak Existensi bagi masyarakat Desa Ongko dalam menggunakan mantra dan tradisi "Maitai Allo Macoa" secara kekinian.

\section{METODE PENELITIAN}

\section{Jenis Penelitian dan Pendekatan}

Metode penelitian yang digunakan dalam penelitian ini ialah metode kualitatif. Data kualitatif merupakan data yang berbentuk kata, kalimat, gerak tubuh, ekspresi wajah, bagan, gambar dan foto
(Sugiyono, 2014:7). Data yang diperoleh di lapangan menggunakan metode kualitatif dan di analisis secara kualitatif dengan pendekatan Semiotik.

\section{Sumber dan Jenis Data}

Sumber data penelitian ini menggunakan data sekunder. Data sekunder adalah data yang diperoleh dari hasil wawancara dengan beberapa informan Masyarakat Desa Ongko Kab. Polewali Mandar (pemangku adat, pawang, dan tokoh masyarakat), hasil pengamatan di lapangan. Adapun jenis data pada penelitian ini berupa naskah dan teks mantra yang diperoleh dari baik informan maupun di kantor desa setempat.

\section{Lokasi dan Waktu Penelitian}

Lokasi penelitian ini terletak di Desa Ongko, Kec. Campalagian, Kab. Polman dan di laksanakan selama 3 bulan, yakni dari bulan Februari 2017 sampai bulan Maret 2017.

\section{Metode dan Teknik Pengumpulan Data}

Metode yang digunakan untuk mengumpulkan data dalam penelitian ini adalah metode observasi. Observasi dilakukan untuk memvalidasi data hasil survei dan mendalami pemahaman responden. Observasi dilakukan selama 2 bulan di tempat-tempat umum di Desa Ongko melalui rekaman dan pencatatan. Selanjutnya, informasi dari masyarakat yang diperoleh merupakan gambaran situasi tentang penggunaan bahasa mantra tradisi "maitai allo macoa" yang sesungguhnya terdapat di lapangan, terutama tingkat penggunaan bahasa itu pada konteks yang tepat. Dari metode tersebut, teknik yang dapat digunakan untuk mendukung metode obeservasi yaitu teknik wawancara dan dokumentasi, teknik ini dilakukan untuk menguatkan hasil survei dan mendalami pemahaman dan penggunaan serta makna semantik dalam penggunaan bahasa mantra dalam tradisi "Maitai Allo Macoa" terhadap responden. Sementara Teknik dokumentasi dilakukan dengan cara mencatat peristiwa yang ada atau sudah 
berlalu di lapangan. Dokumen bisa berbentuk tulisan, gambar, atau karyakarya monumental dari seseorang

\section{Teknik analisis}

Setelah semua data terkumpul, langkah pertama yang dilakukan untuk menganalisis data adalah mentranskrip hasil rekaman tanpa menambahkan atau mengurangi. Langkah selanjutnya adalah mengidentifikasi data yang terkumpul dari hasil rekaman dengan cara memilah mantra yang digunakan dalam tradisi "Maitai Allo Macoa".

Setelah proses identifikasi data selesai, langkah berikutnya adalah menggolongkan dan mengklasifikasikan data yang bersumber dari pertanyaan-pertanyaan yang terdapat dalam hasil wawancara. Pengklasifikasian data berdasarkan penggunaan mantra dalam trdisi "Maitai Allo Macoa" yang digunakan oleh masyarakat tersebut kemudian dikaitkan dengan variabel atau objek penelitian tentang makna mantra serta hubungan antara mantra dalam tradisi "Maitai Allo Macoa".

Berdasarkan ranah penggunaan mantra dalam tradisi berdasarkan variabel-variabel yang telah ditentukan sebelumnya. Setelah proses identifikasi data selesai di lakukan, data dianalisis berdasarkan makna yang terkandung dalam mantra pada tradisi "Maitaii Allo Macoa" dan hubungan antara mantra dan tradisi tersebut terhadap masyarakat Dusun Beru-beru, Desa Ongko. Kemudian setelah proses analisis data selesai dilakukan, disimpulkan makna yang terkandung dalam mantra sebagai karya sastra lisan dan tingkat hubungan antara mantra dan tradisi sebagai wujud dari karya kebudayaan masyarakat Desa Ongko, faktor-faktor dari proses penciptaannya, serta menentukan faktorfaktor yang dominan memengaruhi Masyarakat Desa Ongko dalam menjalankan tridisi "Maitaii Allo Macoa".

\section{Populasi dan Sampel}

Populasi dalam penelitian ini adalah keseluruhan populasi mantra pada masyarakat yang menggunkan mantra dalam tradisi "Maitai Allo Macoa". Pengambilan sampel di Dusun Beru-beru Desa Ongko. Sampel yang refresentatif dipilih dengan cara memilih sampel berdasarkan wilayah dusun yang mewakili Desa dan Kecamatan. Berdasarkan teknik tersebut maka dipilih satu dusun sebagai lokasi penelitian, yaitu sebagai berikut;

Pemilihan wilayah sampel tersebut berdasarkan pertimbangan bahwa:1) Dusun beru-beru merupakan daerah yang dipandang sebagai representatif wilayah pengguanaan Bahasa Mantra dalam tradisi "Maitaii Allo Macoa" yang merupakan pusat tempat tinggal para tokoh-tokoh adat dan dusun tersebut terluas dan terbanyak penduduknya;2) Dusun Beru-beru mewakili wilayah Dusun yang lain terhadap penggunaan bahasa mantra yang berada di Desa Ongko yang ada di Kec. Campalagian.

Hal ini dilakukan karena populasi dianggap seragam (homogen) yang memunkinkan tiap individu berpeluang untuk menjadi sampel penelitian mewakili wilayah dusun yang ada di Desa Ongko tersebut.

\section{Teknik Analisis Data}

Setelah semua data terkumpul, langkah pertama yang dilakukan untuk menganalisis data adalah mentranskrip hasil rekaman tanpa menambahkan atau mengurangi. Langkah selanjutnya adalah mengidentifikasi data yang terkumpul dari hasil rekaman dengan cara memilah mantra yang digunakan dalam tradisi "Maitai Allo Macoa".

Setelah proses identifikasi data selesai, langkah berikutnya adalah menggolongkan dan mengklasifikasikan data yang bersumber dari pertanyaan-pertanyaan yang terdapat dalam hasil wawancara. Pengklasifikasian data berdasarkan penggunaan mantra dalam trdisi "Maitai Allo Macoa" yang digunakan oleh masyarakat tersebut kemudian dikaitkan dengan variabel atau objek penelitian tentang makna mantra serta hubungan 
antara mantra dalam tradisi "Maitai Allo Macoa" .

Berdasarkan ranah penggunaan mantra dalam tradisi berdasarkan variabel-variabel yang telah ditentukan sebelumnya. Setelah proses identifikasi data selesai di lakukan, data dianalisis berdasarkan makna yang terkandung dalam mantra pada tradisi "Maitaii Allo Macoa" dan hubungan antara mantra dan tradisi tersebut terhadap masyarakat Dusun Beru-beru, Desa Ongko. Kemudian setelah proses analisis data selesai dilakukan, disimpulkan makna yang terkandung dalam mantra sebagai karya sastra lisan dan tingkat hubungan antara mantra dan tradisi sebagai wujud dari karya kebudayaan masyarakat Desa Ongko, faktor-faktor dari proses penciptaannya, serta menentukan faktorfaktor yang dominan memengaruhi Masyarakat Desa Ongko dalam menjalankan tridisi "Maitaii Allo Macoa".

\section{HASIL PENELTIAN}

Hasil penelitian ini secara umum berkaitan dengan aspek kesusastraan penggunaan mantra dan naskah "Maitai Allo Macoa" pada masyarakat Desa Ongko. Aspek penggunaan mantra dan naskah "Maitai Allo Macoa" tersebut yakni hubungan antara mantra dan tradisi "Maitai Allo Macoa", Makna yang terkandung dalam tradisi "Maitai Allo Macoa serta dampak yang ditimbulkan dalam penggunaan mantra dan tradisi "Maitai Allo Macoa" pada masyarakat Desa Ongko.

Penelitian ini mengungkapkan bahwa penggunaan mantra dalam tradisi "Maitai Allo Macoa pada masyarakat Desa Ongko meliputi: (1) hubungan antara mantra dan tradisi "Maitai Allo Macoa", (2) Makna mantra yang terkandung dalam tradisi "Maitai Allo Macoa, (3) Dampak yang ditimbulkan dalam penggunaan mantra dan tradisi "Maitai Allo Macoa" pada masyarakat Desa Ongko. Hasil penelitian menunjukkan bahwa terdapat penggunaan mantra dalam tradisi "Maitai Allo Macoa" (1) hubungan antara mantra dan tradisi
"Maitai Allo Macoa", hubungan tersebut dapat dilihat dari tiga pola penggunaannya, yaitu pertama menentukan tujuan penggunaan mantra, kedua memilih waktu dan hari yang dianggap baik dalam naskah "Maitai Allo Macoa dan ketiga membacakan mantra berdasarkan tujuan penggunaan naskah "Maitai Allo Macoa. (2) Mengungkap makna yang terkandung dalam naskah "Maitai Allo Macoa" menggunakan teori semiotika Michael Riffaterre, yaitu makna heuristik dan hermenuitik, matriks dan model dan hubungan intertekstual (3) efek atau dampak esistensi mantra dan tradisi "Maitai Allo Macoa" pada masyarakat Desa Ongko.

\section{PEMBAHASAN}

Penelitian ini menemukan bahwa hubungan penggunaan mantra dan tradisi "Maitai Allo Macoa" pada masyarakat Desa Ongko, makna mantra yang terkandung dalam naskah "Maitai Allo Macoa", serta dampak existensi yang ditimbulkan dalam penggunaan mantra dan tradisi Maitai Allo Macoa" pada masyarakat Desa Ongko. yakni sebagai berikut.

Sebagaimana naskah atau pedoman dasar kehidupan yang terdapat pada uraian hasil penelitian menunjukkan cara menentukan waktu dalam hari yang dianggap baik, berdasarkan arti dan makna yang terdapat dalam simbol-simbol naskah diatas. Adapun waktu yang terdapat dalam naskah pedoman dasar kehidupan atau tradisi "Maitai Allo Macoa" menunjukkan pemilihan waktu dalam menentukan hari yang dianggap baik untuk berangkat memulai kegiatan-kegiatan yang dianggap sakral. Pemilhan hari baik dalam naskah diatas menunjukkan arti dan makna yang terdapat dalam simbol diatas terdapat tabel penyusunan waktu sebagai Pilihan waktu yang dianggap baik untuk menentukan hari yang diaggap baik

Pola kedua, yaitu melihat waktu dan hari yang terdapat dalam naskah kemudian menentukan waktu dan harinya. 
Berdasarkan naskah yang ada pukul 3-6 sore diyakini sebagai hari yang berisi dan dianggap baik untuk berangkat merantau mencari kerja atau menuntut ilmu.

Pola ketiga, yaitu setelah menentukan hari yang baik, semisal, untuk berangkat merantau mencari kerja atau menuntut ilmu. Mantra kemudian dibacakan untuk memudahkan informan meraih apa yang diinginkan, adapun mantra yang dibacakan, yaitu mantra pembueang (bangun tidur), mantra peaqqeang
(Pemberangkatan), mantra assalamakang (keselamatan) peppoleang dalle, mantra kemudian dibacakan.

Dari hasil penelitian yang telah dilakukan oleh penulis, dapat diketahui bahwa jenis tanda yang terkandung dalam naskah" "Maitai Allo Macoa" merupakan tanda yang berjenis icon, berikut dibawah ini penulis akan menguraikan hasil analisis data menggunakan teori semiotika Charles Sanders Pierce

Tabel 1

Tabel makna naskah Maitai Allo Macoa

\begin{tabular}{|c|c|c|c|c|c|}
\hline \multirow{2}{*}{ Hari } & \multicolumn{3}{|c|}{ Tanda } & \multirow{2}{*}{ Makna } & \multirow{2}{*}{ Ket } \\
\hline & Icon & Simbol & Indeks & & \\
\hline \multirow{5}{*}{ Jumat } & 6-8 Pagi & $=$ & $\begin{array}{l}\text { Pulang } \\
\text { Pokok }\end{array}$ & $\begin{array}{l}\text { Upaya yang } \\
\text { ingin dicapai } \\
\text { akan sia-sia. }\end{array}$ & \multirow{5}{*}{$\begin{array}{l}\text { Kesepakatan seca } \\
\text { ra konvensional. }\end{array}$} \\
\hline & $\begin{array}{c}8-11 \\
\text { Dhuha }\end{array}$ & $\varnothing$ & Kosong & $\begin{array}{l}\text { Upaya Akan } \\
\text { menemui kegagalan }\end{array}$ & \\
\hline & $\begin{array}{l}\text { Tengah } \\
\text { Hari 11- } \\
12\end{array}$ & $\mathbf{t}$ & Hidup & $\begin{array}{l}\text { Upaya Akan mengha } \\
\text { silkan kehidupan yan } \\
\text { g lebih baik. }\end{array}$ & \\
\hline & $\begin{array}{c}\text { Dhuhur } \\
12-3\end{array}$ & 0 & Mayat & $\begin{array}{c}\text { Upaya Akan } \\
\text { mendapatkan } \\
\text { celaka. }\end{array}$ & \\
\hline & $\begin{array}{c}\text { Ashar } \\
3-6\end{array}$ & $\square$ & Berisi & $\begin{array}{l}\text { Upaya akan berjalan } \\
\text { sesuai dengan yang } \\
\text { direncanakan }\end{array}$ & \\
\hline & & & Jumlah & & \\
\hline
\end{tabular}




\section{9 | JURNAL ILMU BUDAYA}

Volume 6, Nomor 1, Juni 2018

\section{1) Makna Denotasi}

Denotasi adalah sistem pananda pada level pertama yang menggambarkan relasi penanda dan petanda di dalam tanda, dan antara tanda referennya dalam realitas eksternal (Hasyim, 2014: 71). Dalam iklan televisi, denotasi segala apa yang digambarkan secara visual, atau apa yang direpresentasikan secara fisik. Dari tabel yang terdapat diatas dapat dijelaskan bahwa penggunaan waktu dalam naskah "Maitai Allo Macoa" seperti jam 6-8 merupakan tanda berjenis Icon yang memiliki kemiripan "rupa". pada wujud nyatanya yaitu pagi dimana matahari sudah mulai terbit. Kemudian penggunaan simbol peti mayat dalam naskah "Maitai Allo Macoa" merupakan tanda berjenis Indeks yang menunjuk pada sebuah arti yaitu mati. Ketika menentukan hari baik dengan memilih waktu dan simbol tersebut maka upaya atas yang ingin dicapai oleh pengguna akan menemui celaka.

Penggunaan simbol $=\mathbf{1} \quad \square \quad \square \quad 0 \quad \square$ menunjukkan arti yang telah disepakati secara bersama.

\section{2) Makna Konotasi}

Berdasarkan makna denotasi yang terdapat diatas, maka pada paragraf berikutnya, penulis akan menganalisis dan mengungkap makna denotasi yang terkandung dalam naskah "Maitai Allo Macoa". Dapat dijelaskan bahwa penggunaan waktu dalam naskah "Maitai Allo Macoa" seperti jam 6-8 waktu pagi pada hari sabtu diyakini sebagai hari baik dan berisi, pengertian kata berisi yaitu, Arti kata Berisi yaitu, berisi berarti ada isinya atau tidak kosong, mengandung memuat, padat dan kuat, berarti berilmu; mempunyai kesaktian dan ketika berangkat jam 6-8 waktu pagi pada hari sabtu, maka upaya yang ingin diperoleh dalam merantau menuntut ilmu atau mencari kerja ditanah rantauan akan terwujud dan ketika balik dari tanah rantauan maka kondisi dalam keadaan berisi.
Kemudian makna denotasi pada penggunaan simbol peti mayat dalam naskah "Maitai Allo Macoa" merupakan tanda berjenis Indeks yang menunjuk pada sebuah arti yaitu mati. Ketika menentukan hari baik dengan memilih waktu dan simbol tersebut maka upaya atas yang ingin dicapai oleh pengguna akan menemui celaka.

Penggunaan simbol $=\mathbf{1} \circ \bigcirc \square \square$ menunjukkan arti yang telah disepakati secara konvensional.

Pola kedua, yaitu membacakan mantra. Penggunaan Mantra berdasarkan pada tujuan penggunaan tradisi "Maitai Allo Macoa" itu sendiri. Berikut mantra yang digunakan dalam tradisi "Maitai Allo Macoa" untuk berangkat merantau mencari kerja dan menuntut ilmu ditanah rantauan.

Mengkaji mantra merupakan usaha untuk menangkap makna dan memberi makna kepada isi mantra. Dalam hal ini, Penggunaan mantra dalam tradisi "Maitai Allo Macoa" pada masyarakat Desa Ongko dikaji dengan menggunakan metode semiotik Michael Riffaterre. Yaitu sebagai berikut:

\section{Mantra (1)}

\section{Bismillah.}

\section{I..Ali}

membueq

sisaqu pasaur ilalang sangallona

Kumpayakum dibacakan tiga kali.

Artinya:

Dengan menyebut nama Allah Yang Maha

Pengasih lagi Maha penyayang

Si..Ali bangung

saya sendiri yang berkuasa dalam hari ini

Jadillah

1) Pembacaan Heuristik dan Hermeneutik

a) Pembacaan Heuristik

Mantra ini merupakan mantra pertama yang digunakan ketika akan berangkat merantau. Mantra ini dilafazkan dalam rangka untuk meminta keselamatan ketika 


\section{0 | JURNAL ILMU BUDAYA}

Volume 6, Nomor 1, Juni 2018

akan bangun tidur di waktu pagi. Seperti pada umumnya mantra dalam tradisi "Maitai Allo Macoa" digunakan dalam merantau menuntut ilmu dan mencari kerja. Mantra tersebut terdiri dari satu bait. Setiap baitnya terdiri dari empat baris. Adapun baris pertama terdiri dari dua kata, yaitu I...Ali, I...berarti yang merujuk pada sosok Ali bin Abu Thalib dan membueq artinya bangung, Baris kedua terdiri dari dua kata yaitu sisaqu artinya sendiri dan pasaur berarti kuasa, baris ketiga terdiri dari dua kata, yaitu ilalang berarti didalam dan sangallona yang berarti seharian dan baris keempat kumpayakum , artinya Jadi maka jadilah

\section{b) Pembacaan Hermeneutik}

Mantra di atas sesungguhnya sudah mengimplikasikan keinginanan sipembaca mantra untuk memperoleh kekuatan kebijaksanaan dan kekuasaan dari Tuhan. Pertolongan yang dimaksudkan dalam hal ini adalah berupa sifat bijaksana dan kekuasaan yang dapat diberikan oleh Tuhan.

Penggunaan nama Ali Bin Abu Thalib sebagai sahabat Nabi Muhammad SAW khalifah keempat pada masa kepemimpinan islam, sebagai sosok pribadi yang cerdas, jujur, kuat dan berani arti kata Ali dalam kamus bahasa Indonesia ialah orang yang terpuji. yang membuat orang lain suka, percaya, segang, dan dihormati oleh banyak orang.

\section{2) Matriks dan model}

Mantra ini menggunakan perumpaan kata Ali Bin Abu Thalib Sosok pribadi yang bijaksana, cerdas, jujur, kuat dan berani. Maka dapat dipahami bahwa terdapat keinginan pembaca mantra untuk mendapatkan kehormatan dan agar disegani oleh orang-orang disekelilingnya ditanah rantauan.

Ada satu tanda yang tampaknya monumental dalam mantra ini sehingga dianggap sebagai model, yaitu i..Ali membueq merupakan penanda yang menandai sasaran dari mantra ini. Sesuai dengan fungsinya mantra ini digunakan untuk memeroleh kesuksesan, kecerdasan, kekuasaan dan kehormatan ditanah rantauan.

\section{3) Hubungan intertekstual}

I..Ali mengimplikasikan pada kandungan makna yang terdapat pada Hadis ini diriwayatkan dalam berbagai redaksi. Dzahabi telah meriwayatkannya dalam Al-Mustadrak 'ala AlShahihain 35 dan Dzahabi menegaskannya dalam Talkhish. Redaksi hadis ini adalah demikian:Rasulullah saw bersabda, "Baran g siapa menaatiku, ia telah menaati Allah. Barang siapa melawanku, ia telah melawan Allah. Barang siapa menaati Ali, ia telah menaati-ku. Dan barang siapa melawan Ali, ia telah melawan aku.'Kaitan antara pemaknaan ini dengan fungsi mantra yaitu memperlihatkan adanya suatu upaya untuk menghadirkan jiwa sosok Ali Bin Abu Thalib kedalam diri pembaca mantra agar dapat berkuasa dengan berani dan bijaksana. Dengan demikian, maka orang-orang di sekililingnya di tanah rantauan dapat tunduk dan segan.

\section{Mantra (2)}

Bismillah

Sulo sulona langiq rattinganna allo

Mayallaq lino, mayallaq bulan

Mayallaq duapa iyau Naita anganana tau

Kumpayakum di bacakan tiga kali.

Artinya : Dengan menyebut nama Allah Yang Maha Pengasih lagi Maha Penyayang. Artinya : Dengan menyebut nama Allah Yang Maha Pengasih lagi Maha Penyayang.

Cahaya langit, teriknya matahari

Terangnya dunia, terangnya bulan

Diriku lebih terang dan bercahaya dalam penglihatan orang-orang.

\section{1) Pembacaan Heuristik dan} Hermeneutik

\section{a) Pembacaan Heuristik}

Sulo-sulona langiq pada larik kedua mempunyai arti penerang yaitu cahaya langit yang dapat menerangi bumi dan 


\section{1 | JURNAL ILMU BUDAYA}

Volume 6, Nomor 1, Juni 2018

seluruh isinya, merupakan sebuah perumpamaan yang bermakna energi cahaya langit. Sulo sulona langiq terdiri dari dua kata, yaitu sulo-sulo dan langiq. Sulo-sulo berarti cahaya dan langiq berarti langit. Kata cahaya dapat juga berarti sinar atau cahaya langit berupa energi yang bisa dihisap oleh pembaca mantra agar kelihatan bercahaya. Rattinganna Allo "Teriknya matahari" juga sebuah perumpamaan yang dikiaskan. Kata Rattinganna berarti teriknya yang dapat menyinari seluruh alam. Allo yaitu matahari mempunyai energi yang dapat membantu proses kehidupan di alam semesta.

\section{b) Pembacaan Hermeneutik}

Simbol ketiga sulo-sulo yang menggambarkan keadaan yang terang, sebagaimana cahaya dan sinar. Sulo-sulo adalah penggambaran yang nyata tentang, adanya cahaya dan sinar yang mampu menyinari kegelapan.. Dengan demikian, maka segala gelap akan menjadi terang dan cahaya akan selalu memberikan nilai manfaat dalam proses kehidupan manusia di alam semesta.

\section{2) Matriks dan Model}

Ada dua tanda yang monumental ditemukan dalam mantra ini, yakni sulosulo dan mayallaq. Kedua kata ini masingmasing berperan untuk menimbulkan efek magis pada mantra. Hal ini memberikan penekanan pada efek magis mantra. Kedua kata ini memiliki kekuatan magis yang bermanfaat pada kondisi tertentu.

Kata Mayallaq adalah aktualisasi pertama dari matriks. Perulangan kata ini terdapat pada larik kedua dan ketiga, yang menunjukkan betapa pentingnya kata ini. Sulo-sulo sebagai model pertama mantra, melahirkan beberapa perumpamaan, seperti Mayallaq allo/Mayallaq bulang/Mayallaq duapa iyau/ Kata Mayallaq menjadi muara atau tumpuan dari keseluruhan isi mantra ini.

\section{3) Hubungan Intertekstual.}

Sulo-sulo yang terdapat pada larik pertama mantra mereferensikan pada
Matahari dan Bulan yang menyinari alam dan seluruh isinya. Sulo-sulo memiliki makna yaitu sinar dan cahaya. Seperti itulah yang ingin ditunjukkan oleh kata ini, Hal ini mengingatkan pada apa yang tertulis di dalam Al-Qur'an surat An-Nur ayat 53 yang mana Allah Subhannahu Wa Ta'ala berfirman yang artinya adalah :"Allah itu (pemberi) cahaya (kepada) langit dan bumi, perumpamaan cahayanya seperti relung-relung yang di dalamnya terdapat lampu. Allah mengemukakan banyak perumpamaan kepada manusia. Allah SWT jugalah yang Maha Tahu akan segala sesuatu"."Tempat terbitnya berbagai cahaya Ilahi itu dalam hati manusia dan rahasia-rahasianya" perlu diketahui bahwa hati seseorang sehingga dapat memancarkan cahaya Ilahi itu tidak lain dan tidak bukan adalah sinar ilmu, sinar ma'rifat serta nur tauhid. Cahaya yang keluar dari bintang, bulan juga matahari lebih baik daripada cahaya yang keluar dari hati manusia.

\section{Mantra (3)}

Bismillah.

Irarin diong, inyaman diaya

nyaman para nyaman para tangmangangapa.

Kumpayakum di bacakan tiga kali

Artinya :

Dengan menyebut nama Allah Yang Maha Pengasih lagi Maha Penyayang

Masalah bukan tujuan, kenyamanan diatas segalanya.

Nyaman dalam kenyamanan, semua tanpa ada ap-apa.

Jadilah

\section{1) Pembacaan Heuristik dan Hermeneutik}

\section{a) Pembacaan Heuristik}

Bismillah berarti "dengan menyebut nama Allah". Iraring diong, inyaman diaya terdiri dari Kata iraring diong berasal dari bahasa Mandar, yang berarti, masalah bukan tujuan, Iraring diong adalah sesuatu yang sangat rendah dan harus dihindari. Kata inyaman dapat pula diartikan, yang 
152 | JURNAL ILMU BUDAYA

Volume 6, Nomor 1, Juni 2018

berarti kenyamanan, tidak berada dalam kesusahan, sedangkan diaya yang berarti diatas, selain itu diaya dapat juga diartikan sebagai tempat paling tinggi. Inyaman diaya adalah kenyamaan diatas segalanya.

\section{b) Pembacaan Hermeneutik}

Mantra ini sesungguhnya juga mengandung indeks. Ada tiga tanda indeksikal yang ditemukan dalam mantra ini, yaitu diong, diaya, dan nayaman Kata diong sebagai indeks bermakna terhindar dari masalah didalam perjalanan agar selamat samapi ketujuan. Kata diaya merupakan indeks dari kemampuan untuk melakukan suatu tindakan. Sebagai indeks, kata diaya bermakna tingkat atas yang tinggi. Selanjutnya, kata inyaman sebagai indeks bermakna kenyamanan dan keselamatan. Tanda indeksikal ini mengimplikasikan pada kepercayaan akan kekuatan mahluk gaib yang diyakini sebagai perantara dari tuhan untuk memberi keyamanan dan keselamatan didalam perjalanan menuju ketanah rantauan.

\section{3) Hubungan Intertekstual}

Secara spiritual Tuhan dipahami oleh manusia sebagai Alif Lamm Miim Namun, para sufi memahaminya dalam empat hal, yaitu (1) dzat, yang bukan berawal dan berakhir, bukan rupa, bukan warna, bukan wujud, bukan materi, keadaan yang tenang, tentram, dan damai; (2) sifat, sifat dinamis dari Tuhan yang Maha Bijaksana, adil, dan pengasih dan penyayang; (3) Asma, nama Tuhan yang baik-baik, seperti Allah Ta'ala, Yehueh, Deo, dan God; dan (4) Afngal, hadirnya nasib dan takdir baik dan buruk. Walaupun dzat, sifat, asma, dan afngal dapat dibedakan menurut pengertiannya, tetapi keempatnya merupakan kesatuan yang tidak dapat dipisahkan (Utomo, 1997: 39). Dzat meliputi sifat, sifat menyertai asma, dan asma menandai afngal.

Eksistensi penggunaan mantra dan tradisi "Maitai Allo Macoa" pada masyarakat Desa Ongko, hingga saat ini masih menggunakannya secara turun temurun. Hal tersebut dapat diketahui melalui acara-acara pernikahan yang dilangsungkan oleh masyarakat Desa Ongko. Penggunaan waktu dan hari yang digunakan dalam melangsungkan acara pernikahan dianggap sesuai dengan waktu dan hari baik yang terdapat dalam naskah. Adapun dampak yang ditimbulkan dalam penggunaan mantra dan tradisi "Maitai Allo Maco" pada masyarakat Desa Ongko, selamat berangkat dan pulang dari tanah rantauan dalam keadaan selamat serta kesuksesan dalam meraih ilmu, sehingga dapat memeroleh kesempatan untuk mengabdikan diri sebagai PNS dan mengamalkan ilmu yang diperolehnya pada masyarakat Desa Ongko. .

\section{Simpulan}

Berdasarkan hasil kajian bab sebelumnya (hasil dan pembahasan), penulis dapat menarik beberapa simpulan yang selaras dengan tujuan penelitian, yakni:

Pertama, terdapat tiga pola yang digunakan dalam penggunaan teks mantra dan Naskah "Maitai Allo Macoa" pada masyarakat Desa Ongko yakni (1) menentukan tujuan penggunaan naskah; (2) mencari waktu dalam hari baik yang terdapat dalam naskah; dan (3) membacakan mantra berdasarkan tujuan penggunaan Naskah "Maitai Allo Macoa".

Kedua, kandungan makna yang dipahami terhadap tiga (3) mantra berangkat merantau, menuntut ilmu, dan mencari kerja ditanah rantauan melalui langkah analisis pada bagian sebelumnya dapat disimpulkan sebagai berikut.

Ketiga, eksistensi penggunaan mantra dan tradisi "Maitai Allo Macoa" pada masyarakat Desa Ongko, hingga saat ini masih menggunakannya secara turun temurun. Hal tersebut dapat diketahui melalui acara-acara pernikahan yang dilangsung oleh masyarakat Desa Ongko. Penggunaan waktu dan hari yang digunakan dalam melangsungkan acara pernikahan dianggap sesuai dengan waktu dan hari baik yang terdapat dalam naskah. 


\section{3 | JURNAL ILMU BUDAYA}

Volume 6, Nomor 1, Juni 2018

Adapun dampak yang ditimbulkan dalam penggunaan mantra dan tradisi "Maitai Allo Macoa" bagi Bapak Da'amin, S.Ag., yaitu keselamatan, selamat berangkat dan pulang dari tanah rantauan dalam keadaan selamat serta kesuksesan dalam meraih ilmu, sehingga dapat memeroleh kesempatan untuk mengabdikan diri sebagai PNS dan mengamalkan ilmu yang diperolehnya pada masyarakat Desa Ongko. .

\section{DAFTAR PUSTAKA}

Alwi, Hasan., dkk. 2002. Kamus Besar Bahasa Indonesia (Edisi III). Jakarta: Balai Pustaka.

Arikunto, 2010. Prosedur Penelitian Edisi Revisi 2010.
Hasyim, Muhammad. 2014. Konstruksi Mitos dan Ideologi dalam Teks Iklan Komersial Televisi: Suatu Analisis Semiologi. Disertasi. Makassar: Program Pascarajana Universitas Hasanuddin.

Riffaterre, Michael. 1978. Semiotics of Poetry. Bloomington: Indiana University Press.

Uniawati, 2007. Mantra Melaut Suku Bajo Interpertasi Semiotika riffaterre. (Online). https://core.ac.uk/download/pdf/11 717283.pdf diakses 12 Maret 2012

Van Zoest, Aart, Semiotika: Tentang tanda, Cara Kerjanya dan Apa yang kita lakukan Dengannya (Jakarta: yayasan Sumber Agung:10, 1993. 